\title{
Estrutura e função social da atividade esportiva e o processo de apropriação da cultura: contribuições para a atividade de ensino na Educação Física escolar
}

Antonio Leonan Alves Ferreira?

\section{RESUMO}

Este texto analisa a estrutura e função social da atividade esportiva e o processo de apropriação da cultura, com a finalidade de indicar contribuições para a Atividade de ensino na educação física escolar. Ao tempo em que explicita o lado "positivo" e o "negativo" da contradição sobre a atividade esportiva na sociedade capitalista, avança na análise com a tese de que na atividade esportiva o conceito, imagem subjetiva da realidade objetivada historicamente, realiza-se na corporalidade dos indivíduos, riqueza cultural humana que precisa ser apropriada e objetivada pelos indivíduos na escola. Conclui destacando a necessidade da apropriação das ações/operações acumuladas nos conteúdos clássicos da educação física - as significações objetivas jogo, luta, dança, ginástica etc. - pela via da realização do movimento voluntário, em determinadas condições, cujo motivo mais geral e amplo é o desenvolvimento histórico-social da corporalidade humana, e finalidade é o autodomínio da corporalidade, quando se realiza o sentido da ação; condição para que a educação física contribua com a elevação da capacidade teórico-conceitual dos estudantes na educação escolar.

Palavra-chave: Educação física escolar. Pedagogia histórico-crítica. Metodologia críticosuperadora

1 Doutor em educação. Atualmente trabalha no Instituto Federal de Educação, Ciência e Tecnologia Baiano (IFBA). Catu/Bahia, Brasil. E-mail: leonanferreira@gmail.com

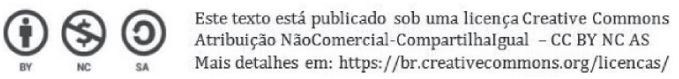




\title{
Structure and the social function of sports activity and the process of appropriation of culture: contributions to the educational activity in Physical Education
}

\begin{abstract}
This text examines the structure and the social function of sports activity and the process of appropriation of culture, with the purpose of indicating contributions to teaching activity in school physical education. At the same time as it explicitly explains the "positive" and "negative" side of the contradiction about sports activity in capitalist society, it advances in the analysis with the thesis that in the activity of sports the concept, subjective image of reality objectified historically, in the corporality of the individuals, human cultural richness that needs to be appropriated and objectified by the individuals in the school. It concludes by highlighting the need to appropriate actions/ operations accumulated in the classical contents of physical education - the objective meanings of game, struggle, dance, gymnastics, etc. - by means of the realization of the voluntary movement, in certain conditions, whose general and broadest motive is the historical-social development of human corporality, and the purpose is the self-mastery of corporeality, when the sense of action is realized; condition for physical education to contribute to raising students' theoretical-conceptual capacity in school education.
\end{abstract}

Keywords: School physical education. Historical-critical pedagogy. Critical-overcoming methodology

Estructura y la función social de la actividad deportiva y el proceso de apropiación de la cultura: contribuciones a la actividad enseñanza en Educación Física

\section{RESUMEN}

Este texto examina la estructura y la función social de la actividad deportiva y el proceso de apropiación de la cultura, con la finalidad de que indica las contribuciones a la docencia en educación física. En el momento en que explicita el lado «positivo» y el «negativo» de la contradicción sobre la actividad deportiva en la sociedad capitalista, avanza en el análisis con la tesis de que en la actividad de deportiva el concepto, imagen subjetiva de la realidad objetivada históricamente, se realiza en la corporalidad de los individuos, riqueza cultural humana que necesita ser apropiada y objetivada por los individuos en la escuela. Concluye destacando la necesidad de la apropiación de las acciones/operaciones acumuladas en los contenidos clásicos de la educación física - las significaciones objetivas juego, lucha, danza, gimnasia etc. - por la vía de la realización del movimiento voluntario, en determinadas condiciones, cuyo motivo más general y amplio es el desarrollo histórico-social de la corporalidad humana, y la finalidad es el autodominio de la corporalidad, cuando se realiza el sentido de la acción; condición para que la educación física contribuya con la elevación de la capacidad teórico-conceptual de los estudiantes en la educación escolar.

Palabra-clave: Educación física escolar. Pedagogía histórico-crítica. Metodología críticasuperadora 


\section{INTRODUÇÃO}

Este texto analisa a estrutura e função social da atividade esportiva e o processo de apropriação da cultura, com a finalidade de indicar contribuições para a "Atividade de ensino na educação física" (FERREIRA, 2015, 2017b). Orienta-se pela tese ${ }^{2}$ que na atividade de esportiva o conceito, imagem subjetiva da realidade objetivada historicamente, realiza-se na corporalidade ${ }^{3}$ dos indivíduos, riqueza cultural humana que precisa ser apropriada e objetivada pelos indivíduos na escola (Idem, ibidem). Assim, ao problematizar a natureza e especificidade deste tipo particular de atividade, afirmamos a necessidade da apropriação das ações/operações acumuladas nos conteúdos clássicos da educação física - as significações objetivas jogo, luta, dança, ginástica etc. - pela via da realização do movimento voluntário (Произвольных движений ${ }^{4}$ ), em determinadas condições, cujo motivo mais geral e amplo é o desenvolvimento histórico-social da corporalidade humana, e finalidade o autodomínio da corporalidade, quando se realiza o sentido da ação; condição para que a educação física contribua com a elevação da capacidade teórico-conceitual dos estudantes na educação escolar (FERREIRA, 2015, 2017b).

\section{RIQUEZA HUMANA UNIVERSAL, MISÉRIA MATERIAL E, HUMANA DA ATIVIDADE ESPORTIVA NA SOCIEDADE CAPITALISTA}

Na sociedade capitalista, no plano mais geral, a atividade esportiva aparece em duas dimensões antagônicas: de um lado, como "rica necessidade humana" - uma objetivação genérica carregada de atividade humana condensada, acumulada -, do outro, como riqueza material e miséria humana - a sua forma Valor (MARX, 2013). Essa dualidade é a expressão contraditória da riqueza humana nesta sociedade.

2 Ver FERREIRA, A. Leonan A. A Atividade de Ensino na Educação Física: a relação dialética entre conteúdo e forma. 258 f. II. 2015. Tese (Doutorado) - Faculdade de Educação, Universidade Federal da Bahia, Salvador, 2015; ver também FERREIRA, Antonio Leonan A. A Atividade de ensino na educação física com fundamento na pedagogia histórico-crítica. Revista Germinal - Marxismo e Educação em debate. Universidade Federal da Bahia. Salvador-Ba. 2017b.

3 A palavra corporalidade vem do latim corpo-ralitas, atis, que significa natureza material, materialidade (HOUAISS, 2008, p. 844). O mesmo que corporeidade, que significa qualidade, propriedade, atributo do que é corporal, portanto, qualidade do que é material, uma forma de desenvolvimento da matéria. Daí dizer que o corpo do homem tem sua gênese no desenvolvimento da atividade prática (MARX, 2007, 2013), uma condição e resultado da experiência específica, da experiência sócio-histórica e ontogenética humana (VYGOTSKI, 2000; LEONTIEV, 2004; LURIA, 1979).

4 Esta é a terminologia no original em russo usada por Zaporozhets (1987) para designar os movimentos voluntários, que pressupõem atividade intencional. O autor também usa Развитие произвольных движений рara referir-se a desenvolvimento dos movimentos voluntários. Para saber mais, no capítulo 05 da tese de Ferreira (2015) foi abordado item sobre a origem e desenvolvimento dos movimentos voluntários segundo o autor russo. Alexander Vladimirovich Zaporozhets, ou, como escrito em russo, Александр Владимирович Запорожец, nasceu em 30.08.1905, corresponde a 12 de setembro pelo calendário antigo, e faleceu em 07.10.1981, mas a sua produção intelectual continua viva. Era psicólogo soviético do desenvolvimento, um estudante de Lev S. Vigotski e Alexei Nikolaevich Leontiev. Zaporozhets estudou os mecanismos psicológicos de movimentos voluntários, percepção e ação, assim como o desenvolvimento do pensamento em crianças. Um dos principais representantes da escola de Kharkov de Psicologia. Ver mais na tese de Ferreira (2015) no endereço: https:// repositorio.ufba.br/ri/handle/ri/22489 
Como rica necessidade humana, a atividade esportiva é uma "totalidade de exteriorização vital", concreta, um sistema de atividade humana particular, complexa, culturalmente formada, que expressa um sentido útil, produzido na relação ativa, consciente, intencional, porém indireta, entre o indivíduo e seu corpo e com os outros indivíduos, relação esta que vem se desenvolvendo desde as formas de organização corporal necessárias à produção dos meios de trabalho com a finalidade de satisfazer carências imediatas, às formas embrionárias de jogos, desde as formas da ginástica na Grécia Clássica, dos espetáculos circenses, dos espetáculos dos gladiadores e das diversas formas de práticas "esportivas" no Império Romano, até as formas mais complexas da atividade esportiva na atualidade. A atividade esportiva é um conteúdo cultural universal, genérico, que precisa ser apropriado pelo conjunto dos seres humanos para que se tornem cada vez mais humanos. O seu sentido útil é produzido na relação entre o desenvolvimento histórico-social da corporalidade e o autodomínio da corporalidade, em condições históricas concretas.

Como riqueza material e miséria humana na sociedade capitalista, a atividade esportiva é uma totalidade abstrata, pois o sentido determinante de sua produção é a reprodução do Valor nesta sociedade. Com essa finalidade a atividade esportiva passa a atender necessidades outras, tendo em vista que os significados hegemônicos dessa atividade são determinados pela forma de alienação das relações de produção e reprodução da vida na sociedade capitalista. No entanto, apesar de ser "saturada" de alienação, uma totalidade abstrata não significa o esgotamento de suas possibilidades, se pensarmos contraditoriamente.

A forma atividade esportiva na sociedade atual alcançou graus extremamente complexos de atividade humana condensada, acumulada, produto das relações ativas e indiretas entre o indivíduo e seu corpo e com os outros indivíduos, a exemplo, identificamos a capoeira, o tênis, o voleibol, a ginástica, o atletismo, a dança etc.

Porém, nem todos tem as condições objetivas e subjetivas para acessar estes conteúdos culturais, quer dizer, o acesso à rica necessidade humana da atividade esportiva não pode ser realizado plenamente na sociedade e na escola capitalista, pois, como afirmou Saviani (2008), a educação escolar é perpassada por uma contradição fundamental: por um lado, a escola tem o papel de socialização do saber sistematizado - ciência, arte, filosofia -, mas, por outro lado, a plena socialização do saber não pode ser realizada na sociedade capitalista.

De acordo com Duarte (2013, p. 243), “a socialização, pela escola, das objetivações genéricas para-si [(arte, ciência, filosofia)] é condição sine qua non para que [o] [...] vir a ser da individualidade para-si se torne um processo presente na vida de todos os seres humanos". Com base neste entendimento o autor afirma que "a escola contribuirá de forma decisiva para a revolução socialista por meio do ensino dos conteúdos escolares" (DUARTE, 2013, p. 243). Segundo Duarte, aqui se coloca a questão da relação entre educação escolar e revolução socialista.

Nessa mesma perspectiva, Saviani afirma que na sociedade capitalista, o saber se converteu em força produtiva, em meio de produção, e como nesta sociedade os meios de produção são propriedade privada, entende-se a dificuldade que ela tem de estender o 
saber para todos (SAVIANI, 2014, p. 24). Diante desta constatação, afirma o autor: “Então a possibilidade de se estender o saber para todos passa pela mudança dessa sociedade, ou seja, pela socialização dos meios de produção que implica a construção de uma sociedade de tipo socialista que supere a ordem capitalista" (SAVIANI, 2014, p. 24), como analisa:

E logicamente a educação - e a escola - participa desse processo e, portanto, cabe sim lutar para que as escolas e a educação possibilitem a compreensão desse movimento. Nesse sentido ela concorre para o desenvolvimento das condições subjetivas necessárias à transformação porque, para que a transformação ocorra, não bastam as condições objetivas; são necessárias também as condições subjetivas. As condições objetivas podem estar maduras para a transformação, mas se não houver o desenvolvimento da consciência dessa necessidade, a mudança não vai ocorrer; e, vice-versa, o desenvolvimento da consciência pode ter amadurecido, mas, faltando as condições objetivas, também a transformação não vai ocorrer. Então a articulação desses dois elementos é fundamental; e a educação aí desempenha um papel importante. E não só a educação em geral, mas também e principalmente a escola (SAVIANI, 2014, p. 24).

Diante disso, afirma Duarte (2013, p. 245-246):

Assim como a socialização da riqueza material só será efetivamente alcançada por meio do socialismo, a realização plena da educação escolar não será alcançada na sociedade capitalista. A pedagogia histórico-crítica entende, divergindo de uma parte do pensamento pedagógico de esquerda, que a escola possui em sua essência uma lógica anticapitalista, no sentido de que a concretização da natureza da educação escolar aponta em direção à universalização do domínio do conhecimento. É por isso que a burguesia apenas valoriza a escola quando esta se circunscreve às elites, e essa mesma burguesia e seus aliados passam a atacar a escola toda vez que ocorre a expansão da escolarização à classe trabalhadora. Tudo isso, porém, acontece de maneira extremamente contraditória ${ }_{\llcorner}$como não poderia deixar de ser em se tratando de um processo movido pela luta de classes.

Corroborando com o suposto acima, Martins (2013, p. 274) afirma que

Todavia, é preciso reconhecer também que a posse dos atributos requeridos à construção do conhecimento objetivo por parte de cada indivíduo é um processo socialmente dependente. Para que tais atributos se desenvolvam, torna-se necessário que forças objetivas operem a esse favor e, [...] atuar nessa direção é a função precípua da educação escolar, à qual compete promover a socialização dos conhecimentos universais, representativos das máximas conquistas científicas e culturais da humanidade, em cuja ausência a captação das leis que regem o desenvolvimento histórico de todos os fenômenos se torna impossível.

Partindo do entendimento de que a natureza da educação escolar aponta em direção à universalização do domínio do conhecimento, esta análise assume como suposto: para que a escola socialize o saber (rica necessidade humana) em suas formas mais desenvolvidas, é necessário enfrentar as contradições no plano geral e no plano particular em 
unidade dialética: no plano geral, trabalhar para a superação da sociedade de classes e, no plano particular, superar o nível de captação sensorial do objeto em favor da apreensão de sua dinâmica interna na Atividade de ensino na educação física escolar. É este aspecto particular que nos interessa nesta análise.

\section{NA ATIVIDADE ESPORTIVA O CONCEITO, IMAGEM SUBJETIVA DA REALIDADE OBJETIVADA HISTORICAMENTE, REALIZA-SE NA CORPORALIDADE}

Diferentemente da atividade científica, na atividade esportiva o conceito, imagem subjetiva da realidade objetivada historicamente, realiza-se na corporalidade. A atividade científica busca explicar o real apreendendo as suas leis efetivas, mediadas por abstrações, conceitos, intencionando superar a aparência do fenômeno, diferentemente da arte, que segundo Duarte (2012, p. 3966), "a aparência é mostrada de outra forma, numa fusão com a essência, num processo que revela ao sujeito a realidade com suas contradições intensificadas, com a acentuação de sua dramaticidade ou de sua comicidade", quer dizer, "[...] o caminho [...] não é o do afastamento em relação à aparência [...]", como faz a ciência. Para Duarte (2012, p. 3966), "Se a ciência trabalha com as abstrações, com os conceitos, a arte trabalha com imagens da realidade, sejam essas imagens captáveis por alguns dos sentidos humanos, sejam imagens literárias que passam pela mediação da linguagem".

De acordo com o autor, "a relação do indivíduo com essas imagens artísticas da realidade é imediata, da mesma forma como é imediata a relação do indivíduo com as vivências da cotidianidade. Ocorre que a imediatez da arte tem resultados e objetivos distintos da imediatez da vida cotidiana", que "visa resultados práticos, satisfação de necessidades imediatas. Já no caso da imediatez da arte, a prática é suspensa, as necessidades imediatas ficam para outro momento e prevalece a entrega ao 'mundo' da obra de arte", como esclarece:

\footnotetext{
Momentaneamente o indivíduo age não para atingir resultados práticos, mas para viver a relação imediata com a obra de arte, uma relação que se dirige ao conteúdo da obra, mas é dirigida por sua forma, num processo em que o indivíduo está em contato com a aparência, mas esta o conduz a questões essenciais à vida humana (DUARTE, 2012, p. 3966).
}

Assim, Duarte (2012, p. 3964) afirma com base em Lukács, que a arte é antropomórfica, pois se volta ao domínio do humano, já a ciência é desantropomórfica, pois “os conhecimentos científicos se situam no domínio da universalidade e buscam a desantropomorfização, no sentido de restringir a influência dos aspectos subjetivos, humanos na compreensão dos fenômenos", continua o autor:

Além disso, o processo de desantropomorfização também remete ao princípio de que a natureza tem uma dinâmica de funcionamento imanente. Um exemplo bastante emblemático é o de que não existe teleologia na natureza. Assim como não 
existe criação na natureza. Ela não foi criada e nela não há o ato de criação. Esse ato só surgiu com a atividade teleológica humana, ou seja, com o trabalho (DUARTE, 2012, p. 2964).

Segundo o autor, "A desantropomorfização é um processo no qual se procura explicar a natureza sem se recorrer a fenômenos existentes apenas na cultura e na sociedade como produtos das ações humanas" (DUARTE, 2012, p. 3964). "Em contrapartida, o reflexo artístico da realidade volta-se exatamente para o mundo dos seres humanos, das relações humanas e da sensibilidade humana. Nesse sentido a arte é antropomórfica" (DUARTE, 2012, p. 3964). Entretanto, "A cada descoberta que faz época nas ciências naturais, a cada revolução social, cada vez que se cria uma grande obra de arte, transforma-se o aspecto do mundo, e bem assim - especial e essencialmente - a própria posição do homem no mundo" (KOSIK, 2011, p. 215).

Por sua vez, a atividade esportiva é antropomórfica. Seu motivo pode ser classificado em duas dimensões: por um lado, possui um motivo geral, historicamente determinado, a saber: o desenvolvimento histórico-social da corporalidade humana; por outro, a atividade esportiva possui motivos particulares, em que expressam formas lúdicas, estéticas, agonísticas, competitivas, todos elementos completamente carregados do humano - uma condição para que a atividade esportiva se desenvolva. No caso dos motivos particulares, as ações/operações interpostas na atividade definirão a preponderância de um ou outro motivo, podendo um mesmo conteúdo conter mais de um motivo particular, a depender da estrutura da atividade.

A síntese acima tem implicações importantíssimas na apreensão da estrutura e função social da atividade esportiva quando comparada à atividade científica e à atividade artística. Estamos afirmando que a atividade esportiva não visa explicar as leis efetivas da realidade a partir de abstrações (ciência), mas também, em sua especificidade, não tem por finalidade a produção de imagens no sentido artístico (arte), sejam essas captáveis por sentidos humanos ou imagens literárias que passam pela mediação da linguagem, como afirmou Duarte. A produção de imagens artísticas pode se constituir como ações/fins na atividade esportiva, atreladas a motivos particulares, mas não constitui a sua finalidade mais geral. Até mesmo em uma competição que envolva o critério artístico, como é o caso da patinação artística, apesar de conter o critério da beleza, plasticidade dos movimentos, construção de uma imagem artística, aproximando-nos ao campo da arte, a sua finalidade mais geral será a realização do autodomínio da corporalidade pelo indivíduo na relação ativa e indireta, mediada, com seu corpo e com os outros indivíduos/sociedade. Portanto, o seu resultado "não" é preponderantemente uma imagem artística, pois, como já sinalizamos, nessa forma particular de atividade humana, a imagem, subjetivação do objetivado historicamente, realiza-se na corporalidade dos indivíduos que, pela via da apropriação das ações/operações acumuladas nos conteúdos da atividade esportiva, exterioriza-se na forma de movimentos voluntários, em direção ao autodomínio da corporalidade, sua forma objetivada. 
Assim, na atividade esportiva as ações em seus fins específicos são orientadas ao domínio cada vez mais ativo, consciente e intencional do indivíduo sobre seu corpo, perspectivando atingir determinado objetivo particular, por exemplo, saltar o mais alto ou mais distante possível, correr o mais rápido possível, executar a ação corporal com precisão a fim de marcar o ponto e assim atingir o objetivo imediato do jogo, executar determinada ação com plasticidade, controlar o corpo no espaço etc. Para tanto, faz isso na base de operações que colaboram para atingir o resultado da ação. A ação, portanto, carrega significados (conceitos) com maior grau de complexidade, ou, poderíamos dizer, maior grau de atividade humana acumulada. As operações, apesar de serem essenciais para o desenvolvimento de ações mais complexas, carregam menor grau de complexidade, mas constituem a base, a condição para a realização das ações, pois sem estas as ações não poderiam sequer ser realizadas; por exemplo, o equilíbrio, a orientação espacial e temporal, a lateralidade, a força, a velocidade, todas são operações que consubstanciam a elaboração de novas ações na atividade esportiva complexa; porém, se estivermos desejando formar no estudante, por exemplo o equilíbrio, este seria o objeto da ação, portanto a ação mesma. Estamos afirmando isto para explicar que há uma dinâmica de transformação nesse processo de formação de novas ações, em que um conceito vai sendo incorporado ao outro, dando fundamento para que o mais elaborado se desenvolva, mas sempre tomando como referência a relação todo-análise-novo todo. Portanto, atingir o objetivo imediato do jogo não esgota o conteúdo dessa atividade, tendo em vista a pluralidade de motivos particulares que a constitui. Vamos aprofundar mais.

No processo de apropriação da atividade esportiva, a relação dos indivíduos com os conteúdos da atividade na realidade é imediata, da mesma forma que ocorre com as relações dos indivíduos com os objetos na vida cotidiana. Ocorre que a imediatez da atividade esportiva tem resultados e objetivos distintos da imediatez da vida cotidiana. Como dissemos, esta visa resultados práticos, satisfação de necessidades imediatas. Já no caso da imediatez na atividade esportiva, a prática é suspensa, pois, como afirmou Kosik, "[...] sem a objetivação não se dá suspensão temporal ${ }^{5 "}$. Ocorre que as necessidades imediatas ficam para outro momento e prevalece a entrega ao jogo, no qual, mediado por significações objetivas realizadas historicamente, produz motivos nos indivíduos que extrapolam a dimensão da vida cotidiana, da produção e reprodução da pura sobrevivência, e aqui aparece o conteúdo das emoções, sentimentos e pensamento humano, muito próximos ao campo da arte. Porém, mediatamente, a relação produzida na atividade imediata, como uma segunda imediatez, vai possibilitar ao indivíduo a apropriação de uma atividade humana complexa produzida historicamente pelo domínio cada vez mais ativo, consciente e intencional pelos indivíduos da estrutura e função social desta atividade, pois o indivíduo age para se apropriar das significações objetivas acumuladas no objeto cultural (conteúdos) e, ao fazer, se relaciona ativa e indiretamente com os conteúdos. Ao tempo em que

5 Segundo Kosik (2011, p. 204), "Neste ponto fundamental, em que a problemática do tempo humano é associada à atividade objetiva do homem, a filosofia materialista se diferencia essencialmente da concepção existencialista da temporalidade". 
os indivíduos se apropriam de forma consciente das operações, interpostas pelas ações exteriores no ensino, as significações objetivas vão se realizando na sua corporalidade na forma de hábito, habilidade, automatizando conteúdos e formando capacidades. Isso significa que a imagem do objeto que vai sendo apropriada pelo sujeito passa de relações diretas e imediatas a relações indiretas e mediadas, numa relação cada vez mais ativa, consciente, intencional e crítica com o seu corpo.

Isso significa que também na atividade esportiva, assim como na arte, a apropriação inicial da atividade se dá pela sua forma imediata, pela forma do fenômeno, quer dizer: aprende-se o jogo, a luta, a ginástica, a dança, a patinação, realizando as ações/ operações que constituem a atividade, e gradativamente (de forma mediada) o indivíduo vai aprendendo as suas propriedades mais essenciais e fundamentais, diferenciando-as de outras formas de atividade, tais como a ciência, em que, como dissemos, para realizar, o indivíduo precisa se apropriar, antes de mais nada, de um sistema complexo de abstrações. Todavia, diferentemente da arte, em que a sua forma o conduz ao sentimento humano objetivado numa obra de arte, na atividade esportiva a forma da atividade vai conduzindo o indivíduo ao desenvolvimento da sua corporalidade e, nesse processo, ao se apropriar das significações objetivas, motivos particulares vão colocando os indivíduos em contato com sentimentos humanos produzidos na história do gênero pela atividade.

Portanto, a objetivação do conteúdo da atividade esportiva se dá na medida em que o indivíduo joga. Assim, não é possível se apropriar do conteúdo da atividade esportiva sem o estabelecimento de uma relação ativa, consciente e intencional e crítica, porém indireta, do indivíduo com seu corpo, com os outros indivíduos/sociedade.

Para realizar alguns apontamentos sobre como se realiza essa dinâmica na estrutura da atividade esportiva, tomaremos um pequeno recorte do caso do jogador de voleibol: quando este golpeia a bola e atinge o chão da quadra oposta, efetua uma ação bem determinada. Como se caracteriza esta ação/operação-fins? Em primeiro lugar, evidentemente, pela atividade em que se insere, pelo seu motivo e, portanto, pelo sentido que ela tem para o indivíduo que a efetua. Mas ela caracteriza-se também pelos processos e operações através dos quais se realiza. Um golpe efetivo no voleibol requer numerosas operações, cada uma respondendo às condições determinadas da ação dada: é necessário assumir uma certa pose, estabelecer a distância correta da bola para poder realizar maior impulsão e explosão no salto, bem como seguir corretamente na linha da bola, a depender da jogada planejada, observar o bloqueio "oponente" antes e durante o salto, girar o braço com velocidade e golpear a bola com força em direção ao chão da quadra oposta, utilizando os espaços abertos no bloqueio para que a bola possa passar ou "explorar o bloqueio" (forma de fazer com que a bola "espalhe" ao bater no bloqueio e assim se consiga o ponto). Tudo isso dependerá da altura do bloqueio e da impulsão que o oponente alcançar para golpear a bola, além da capacidade do jogador para agir com intencionalidade e ainda mudar sua decisão em virtude da situação do bloqueio ou de uma bola que não tenha sido levantada com qualidade, e ainda de suas condições físicas para tal, a habilidade para girar o braço com velocidade, etc. Vejam a complexidade deste conteúdo! Continuamos. Para o jogador experimentado, esses diferentes processos não são ações diferentes. Os fins correspondentes 
não se distinguem na sua consciência. O jogador não diz "agora eu devo me distanciar da rede, onde a bola será levantada, ficar na linha da bola" etc. Na sua consciência, só há um único fim: golpear a bola ao chão da quadra oposta. Isso significa que ele domina as operações que o golpe exige. A coisa é absolutamente diferente naquele que se inicia no voleibol. Deve primeiro ter por fim a aprendizagem dos instrumentos do jogo, da dinâmica do jogo, e para isso terá que "jogar" inicialmente o voleibol; em seguida, a sua ação consciente consiste em aprender a golpear a bola, a receber a bola com a manchete, a defender a bola, a bloquear a bola, a olhar o bloqueio, a girar o corpo no ar a fim de mudar a rota da bola e conseguir espaço aberto no bloqueio etc., claro, todo este processo se realizará num período de ensino-aprendizagem-desenvolvimento, num processo de vai das operações-ações-atividade, tendo como referência a relação atividade-ações-operações.

Ao analisar a aprendizagem do voleibol ou qualquer outra atividade complexa, vimos que os elos que a compõe se formam inicialmente como ações separadas e só se transformam em operações ulteriormente. Na consciência do jogador de voleibol experiente, por exemplo, as operações que consistem em ajustar o golpe ou definir a direção para onde seguirá a bola (paralela, diagonal, centro, fundo, atrás do bloqueio etc.) podem não estar presentes. Parafraseando Leontiev (2004), basta, todavia, o menor desvio em relação à execução normal da operação para que esta última, bem como as suas condições materiais, apareça nitidamente à consciência. Mas, por o jogo de voleibol possuir um conteúdo bastante dinâmico, muitas operações aparecem com certa frequência, até mesmo para o jogador experiente; mas a diferença é que este já possui conteúdo para agir de forma a superar algumas das condições inesperadas na atividade.

Assim, no processo de apropriação dos conteúdos da atividade esportiva, cada ação consciente vai fixando operações motoras auxiliares e vão constituindo as condições para o desenvolvimento de novas ações na atividade, em condições determinadas. Quando o fim de uma ação entra numa segunda ação, enquanto condição de sua realização, ela se transforma em meio para realizar a segunda ação, quer dizer, tornou-se operação consciente e só por isso foi possível esta relação. Este processo realizado na Atividade de ensino na educação física cria as condições para o desenvolvimento do pensamento nos indivíduos para além das formas imediatas da realidade, pois exige atividade consciente. Mas não somente, é preciso realizar o conjunto de significados que constituem estas ações/operações na atividade como produção histórico-social. Aqui está um desafio para os estudos do campo acadêmico da educação escolar.

\section{CONSIDERAÇÕES FINAIS}

Na linha da pedagogia histórico-crítica e da psicologia histórico-cultural, estamos entendendo que a educação física precisa enfrentar as contradições em todas as suas instâncias, em especial na educação escolar, por meio do trabalho educativo - o ato de produzir o gênero humano em cada indivíduo singular (SAVIANI, 2012). 
julho/2018

Para enfrentar estas contradições na particularidade da atividade de ensino na educação física, estamos defendendo a necessidade da transmissão dos conhecimentos clássicos da disciplina escolar educação física em suas formas mais desenvolvidas. Os conteúdos da educação física têm na atividade esportiva a sua forma mais desenvolvida porque esta expressa graus elevados de desenvolvimento das relações ativas, conscientes, intencionais, e críticas, porém indiretas, entre o indivíduo e seu corpo, o indivíduo com os outros indivíduos/sociedade. A atividade esportiva é uma forma de objetivação genérica, uma atividade constituída por uma base material orgânica (morfofisiológica) em unidade contraditória (não antagônica) com a materialidade do objeto social contido nesta objetivação. O seu motivo mais geral é o desenvolvimento histórico-social da corporalidade humana, e finalidade o autodomínio da corporalidade, cujo sentido da ação é a realização da imagem subjetiva da realidade objetivada historicamente, na corporalidade dos indivíduos. Tem como significações objetivas a serem apropriadas pelas crianças, adolescentes, jovens e adultos na escola para tal realização as ações/operações acumuladas nos conteúdos da educação física - jogo, luta, dança, ginástica etc. - pela via da realização do movimento voluntário, em determinadas condições, cuja finalidade mais ampla, na educação escolar, é contribuir na elevação da capacidade teórico-conceitual dos estudantes. Quando falamos que o ser humano realiza movimentos voluntários estamos afirmando uma qualidade da atividade humana, produto da atividade prático-histórica. Isto significa que os movimentos voluntários são produtos históricos, acumulados em formas objetivadas da realidade (significações objetivas), que desde as suas formas embrionárias já exigem atividade consciente e intencional; são produtos de uma relação ativa e indireta entre o indivíduo e seu corpo, indivíduo e outros indivíduos/sociedade, mediada. Isto significa que: histórico-socialmente, quanto mais a atividade se complexifica, mais a necessidade passa de condição para a atividade a resultado da atividade, dando origem a objetos culturais cada vez mais condensados de atividade humana. Assim, podemos afirmar que a corporalidade humana é um objeto histórico, é um "ato de nascimento que se supera" (MARX, 2007). Por outro lado, podemos também afirmar que os animais possuem corporalidade, no entanto, as leis que a determina são puramente naturais. Aqui está posto um conjunto de relações que produz o sentido útil da atividade esportiva.

\section{REFERÊNCIAS}

DUARTE, Newton. O Marxismo e a Questão dos Conteúdos Escolares. ANAIS ELETRÔNICOS DO IX SEMINÁRIO NACIONAL DE ESTUDOS E PESQUISAS "HISTÓRIA, SOCIEDADE E EDUCAÇÃO NO BRASIL". Universidade Federal da Paraíba - João Pessoa - 31/07 a 03/08/2012. Acesso: http://www.histedbr.fe.unicamp. br/acer_histedbr/seminario/seminario9/. $4915 \mathrm{p}$.

DUARTE, Newton. A individualidade para-si. $3^{\text {a }}$ ed. (revisada). Campinas, SP: Autores Associados, 2013. 254 p. 
FERREIRA, Antonio Leonan Alves. A Atividade de Ensino na Educação Física: a relação dialética entre conteúdo e forma. 258 f. II. 2015. Tese (Doutorado) - Faculdade de Educação, Universidade Federal da Bahia, Salvador, 2015.

FERREIRA, Antonio Leonan Alves. Atividade e desenvolvimento humano: contribuições para a pesquisa em educação escolar. Germinal: Marxismo e Educação em Debate, Salvador, v. 9, n. 1, p. 248-265, mai. 2017a. ISSN 2175-5604. Disponível em: < https:// portalseer.ufba.br/index.php/revistagerminal/article/view/17224>. Acesso em: $15 \mathrm{Fev}$. 2018. doi:http://dx.doi.org/10.9771/gmed.v9i1.17224.

FERREIRA, Antonio Leonan Alves. A atividade de ensino na educação física com fundamento na pedagogia histórico-crítica. Germinal: Marxismo e Educação em Debate, Salvador, v. 9, n. 2, p. 108-120, set. 2017b. ISSN 2175-5604. Disponível em: < https://portalseer. ufba.br/index.php/revistagerminal/article/view/17494>. Acesso em: 15 Fev. 2018. doi:http://dx.doi.org/10.9771/gmed.v9i2.17494.

HOUAISS, 2008. Grande dicionário Houaiss da língua portuguesa. Rio de Janeiro: Editora Objetiva, 2008. 2922 p.

KOSIK, Karel. Dialética do concreto. Tradução de Célia Neves. $2^{\mathrm{a}}$ ed. (9a reimpressão). Rio de Janeiro: Paz e Terra, 2011. 250 p.

LEONTIEV, Alexis. O desenvolvimento do psiquismo. ed. 2a . São Paulo: Centauro, 2004. $355 \mathrm{p}$.

LURIA, Alexander R. Curso de psicologia geral. Vol I. Tradução de Paulo Bezerra. Rio de Janeiro: Civilização Brasileira, 1979. 115 p.

MARTINS, Lígia M. O desenvolvimento do psiquismo e a educação escolar: contribuições à luz da psicologia histórico-cultural e da pedagogia histórico-crítica. Campinas, SP: Autores Associados, 2013. 319 p.

MARX, Karl. A ideologia alemã: crítica da mais recente filosofia alemã em seus representantes Feuerbach, B Bauer e Stirner, e do socialismo alemão em seus diferentes profetas. Tradução de Rubens Enderle, Nélio Shneider e Luciano Cavini Martorano. São Paulo: Boitempo, 2007. 614 p.

MARX, Karl. O capital: crítica da economia política. Livro I: o processo de produção do capital. Tradução de Rubens Enderle. São Paulo: Boitempo, 2013. 894 p.

SAVIANI, Dermeval. Escola e democracia. Edição comemorativa. Campinas, SP: Autores Associados, 2008. $112 \mathrm{p}$.

SAVIANI, Dermeval. Pedagogia histórico-crítica: primeiras aproximações. $11^{\mathrm{a}}$ ed. (revisada). Campinas, SP: Autores Associados, 2012. 137 p.

SAVIANI, Dermeval. A pedagogia histórico-crítica. Revista Binacional Brasil-Argentina. V. 03, nº 02, p. 11-36. Vitoria da Conquista-Ba, dezembro de 2014.

VYGOTSKI, Lev S. Obras Escogidas. Vol III. Traducción de Lydia Kuper. Madri: Visor, 2000. 383 p.

ZAPOROZHETS, A. V. Estudio psicológico Del desarrollo de la motricidad em el niño preescolar. IN: BIBLIOTECA DE PSICOLOGÍA SOVIÉTICA. La psicologia evolutiva y pedagógica em la URSS. Antologia. La Habana, Cuba: Editorial Progresso. 1987. 350 p. 
julho/2018

No original russo em: Cuestiones de psicología del niño preescolar. Bajo la redacción de A. Leontiev y A. Zaporózhets. Moscú. Ed. de la Academia de Ciencias Pedagógicas de la RSFSR, 1948, p. 102-112.

Recebido em: Março/2017 Aprovado em: Agosto/2017 